\title{
Comparison of influenza vaccine effectiveness in preventing outpatient and inpatient influenza cases in older adults, northern Spain, 2010/11 to 2015/16
}

Jesús Castilla ${ }^{1,2}$, Iván Martínez-Baz ${ }^{1,2}$, Ana Navascués ${ }^{3}$, Itziar Casado ${ }^{1,2}$, Aitziber Aguinaga³, Jorge Díaz-González ${ }^{1}$, Josu

Delfrade $^{1,2}$, Marcela Guevara ${ }^{1,2}$, Carmen Ezpeleta ${ }^{3}$, Primary Health Care Sentinel Network of Navarre ${ }^{4}$, Network for Influenza Surveillance in Hospitals of Navarre 4

1. Instituto de Salud Pública de Navarra, IdiSNA - Navarre Institute for Health Research, Pamplona, Spain

2. CIBER Epidemiología y Salud Pública (CIBERESP), Madrid, Spain

3. Complejo Hospitalario de Navarra, IdiSNA - Navarre Institute for Health Research, Pamplona, Spain

4. The members of the networks are listed at the end of the article

Correspondence: Jesús Castilla (jcastilc@navarra.es)

Citation style for this article:

Castilla Jesús, Martínez-Baz Iván, Navascués Ana, Casado Itziar, Aguinaga Aitziber, Díaz-González Jorge, Delfrade Josu, Guevara Marcela, Ezpeleta Carmen, Primary Health Care Sentinel Network of Navarre, Network for Influenza Surveillance in Hospitals of Navarre. Comparison of influenza vaccine effectiveness in preventing outpatient and inpatient influenza cases in older adults, northern Spain, 2010/11 to 2015/16. Euro Surveill. 2018;23(2):pii=16-o0780. https://doi. org/10.2807/1560-7917.ES.2018.23.2.16-00780

Article submitted on 30 Nov 2016 / accepted on 15 Feb 2017 / published on 11 Jan 2018

Introduction: We compared trivalent inactivated influenza vaccine effectiveness (VE) in preventing outpatient and inpatient influenza cases in Navarre, Spain. Methods: During seasons 2010/11 to 2015/16, community-dwelling patients with influenza-like illness aged 50 years or older were tested for influenza when attended by sentinel general practitioners or admitted to hospitals. The test-negative design was used to estimate and compare the VE by healthcare setting. Results: We compared 1,242 laboratory-confirmed influenza cases (557 outpatient and 685 inpatient cases) and 1,641 test-negative controls. Influenza VE was $34 \%$ ( $95 \%$ confidence interval (CI): 6 to 54 ) in outpatients and $32 \%$ (95\% Cl: 15 to 45 ) in inpatients. VE in outpatients and inpatients was, respectively, 41\% (95\% Cl: -1 to 65$)$ and $36 \%(95 \% \mathrm{Cl}: 12$ to 53 ) against $\mathrm{A}\left(\mathrm{H}_{1} \mathrm{~N}_{1}\right)$ pdmo9, $5 \%(95 \% \mathrm{Cl}:-58$ to 43$)$ and $22 \%(95 \% \mathrm{Cl}:-9$ to 44$)$ against $\mathrm{A}\left(\mathrm{H}_{3} \mathrm{~N}_{2}\right)$, and $49 \%(95 \%$ $\mathrm{Cl}, 6$ to 73$)$ and $37 \%(95 \% \mathrm{Cl}: 2$ to 59$)$ against influenza $B$. Trivalent inactivated influenza vaccine was not associated with a different probability of hospitalisation among influenza cases, apart from a 54\% (95\% $\mathrm{Cl}: 10$ to 76$)$ reduction in hospitalisation of influenza $\mathrm{A}\left(\mathrm{H}_{3} \mathrm{~N}_{2}\right)$ cases. Conclusions: On average, influenza VE was moderate and similar in preventing outpatient and inpatient influenza cases over six influenza seasons in patients above 50 years of age. In some instances of low VE, vaccination may still reduce the risk of hospitalisation in older adults with vaccine failure.

\section{Introduction}

Annual influenza epidemics are associated with large numbers of medical consultations and hospitalisations. Most influenza patients are seen in general practice, but sometimes influenza evolves to serious forms or worsens underlying chronic conditions and requires hospitalisation. Certain risk groups and older adults with influenza are at increased risk of hospitalisation [1-3].

In most seasons, influenza vaccine is moderately effective (around 50\%) in preventing influenza cases [4-9]; however, there is little information on whether it is equally effective in preventing outpatient and inpatient (hospitalised) cases [10]. Vaccine effectiveness (VE) estimates obtained from the general practice and hospital settings in the same area and season may be expected to be similar since they evaluate the same types of influenza vaccine against the same circulating virus. However, inpatient cases tend to be older and to present more underlying chronic conditions, so they are more likely to be affected by immunodepression and immunosenescence, which could reduce the influenza vaccine effect [11]. In studies, most of these factors can be controlled for in multivariate analyses. However, a higher VE could be observed in hospitalised patients if the influenza vaccine mitigates influenza illness severity, reducing the risk of hospital admission in people in whom it did not prevent influenza infection [8].

The test-negative case-control design that compares laboratory-confirmed influenza cases and test-negative controls [12], has been widely used to evaluate influenza VE in preventing laboratory-confirmed influenza. This design was employed to evaluate outpatient [13-16] and inpatient cases $[17,18]$. However, very few studies obtained influenza VE estimates in the general practice and hospital settings for the same influenza season and population [19-21], and none of them provided conclusive comparisons of both estimates [10]. 
As influenza VE may differ from season to season, pooled analysis of several seasons is used to obtain average estimates [15-22].

Our test-negative case-control study nested in a population-based cohort aims to estimate trivalent inactivated influenza VE in preventing outpatient and inpatient cases with laboratory-confirmed influenza among community dwelling adults aged 50 years or older throughout six influenza seasons, and to identify possible differences in VE between the general practice and hospital settings.

\section{Methods}

\section{Study population and setting}

This study was performed in the region of Navarre (642,000 inhabitants), Spain, during the influenza seasons $2010 / 11$ to $2015 / 16$. Six seasons were included to assure a larger size of the study population and periods with circulation of the influenza viruses $A\left(\mathrm{H}_{1} \mathrm{~N}_{1}\right)$ pdmo9, $A\left(\mathrm{H}_{3} \mathrm{~N}_{2}\right)$ and $B$. The Navarre Health Service provides primary and hospital healthcare, free of charge, to over $95 \%$ of the population. Since 2009 , influenza VE has been evaluated annually, using a test negative case-control design nested in a populationbased cohort, including patients from sentinel general practitioners and hospitals [21,23-25]. The Navarre Ethical Committee for Medical Research approved the study protocol.

Each influenza season, the non-adjuvanted inactivated trivalent vaccine was recommended and offered free of charge to people aged 60 years or older, and to patients with major chronic conditions (heart disease, lung disease, renal disease, cancer, diabetes mellitus, liver cirrhosis, dementia, cerebral stroke, immunocompromised, and body mass index of $40 \mathrm{~kg} / \mathrm{m}^{2}$ or greater) [26]. The vaccination programme distributed a single brand of trivalent inactivated vaccine in each influenza season. People not covered by the recommendation could also be vaccinated if they purchased the vaccine in pharmacies.

Influenza surveillance was based on automatic reporting from the electronic medical records of all cases of influenza-like illness (ILI) diagnosed in primary healthcare centres and hospitals. ILI was considered to be the sudden onset of any general symptom (fever or feverishness, malaise, headache or myalgia) in addition to any respiratory symptom (cough, sore throat or shortness of breath) [27]. A sentinel network composed of a representative sample of 76 to 80 primary healthcare physicians was asked to take double swabs, nasopharyngeal and pharyngeal, from all patients diagnosed with ILI whose symptoms had begun less than 5 days previously. The protocol for influenza management in hospitals establishes early detection and nasopharyngeal and pharyngeal swabbing of all hospitalised patients with ILI. Swabs were processed by reverse transcription PCR (RT-PCR) assay in the microbiology departments of the Navarre Hospital Complex and the Navarre University Clinic.

The present study included ILI cases aged 50 years or older attended in primary healthcare (outpatients) or hospitalised (inpatients) who were swabbed during the study period. Healthcare workers, persons living in nursing homes, patients hospitalised less than 24 hours, and patients who were hospitalised before ILI symptom onset were excluded. For each influenza season, the study period was defined as November to May of the following year.

Influenza vaccine status was obtained from the regional vaccination register. Subjects were considered to be protected 14 days after vaccine administration.

The information on sex, age, major chronic conditions (heart disease, respiratory disease, renal disease, cancer, diabetes mellitus, liver cirrhosis, dementia, cerebral stroke, immunocompromised, rheumatic disease, and body mass index $\geq 40 \mathrm{~kg} / \mathrm{m}^{2}$ ), functional dependence (Barthel index score $<40$ ), previous hospitalisation, and month of sample collection was obtained from the electronic clinical records.

\section{Study design and statistical analysis}

A double test-negative case-control design in outpatients and inpatients, both nested in the same population-based cohort, was used to compare the vaccination status of ILI patients with laboratory-confirmed influenza and test-negative controls.

Percentages were compared by chi-squared test. Logistic regression models were used to obtain crude and adjusted odds ratios (OR) for influenza vaccination with their $95 \%$ confidence interval $(\mathrm{Cl})$. In addition to healthcare setting (primary or hospital), the adjusted models included sex, age group (50-59, 60-69, $70-79$, and $\geq 80$ years), major chronic conditions $(0, \geq 1)$, functional dependence, hospitalisation in the previous 12 months, and influenza season and month of sample collection. VE was estimated as a percentage: $(1-O R)$ x 100.

Cases were compared with controls recruited in the same healthcare setting to obtain VE estimates for all patients and separately for outpatient and inpatient cases. Separate analyses were also carried out by age group (50-64 years and $\geq 65$ years), influenza (sub) type, presence of major chronic conditions, and influenza season. Although stratum-specific VE estimates were obtained from stratified models, we also tested the statistical significance of the interaction term among these variables and vaccine status.

The VE estimates obtained from outpatients and inpatients may not be comparable since these two groups usually differ in many characteristics. Therefore, in an adjusted analysis we compared the odds of vaccination of inpatient cases vs outpatient cases to estimate the 
Influenza vaccine effectiveness in preventing laboratory-confirmed cases by (sub)type of virus and healthcare setting in northern Spain, 2010/11 to 2015/16

Cases Controls (\% vaccinated) (\% vaccinated $)$

Unadjusted vaccine effectiveness, \% $(95 \% \mathrm{Cl})$

All swabbed patients

$\begin{array}{lll}\text { All patients } & 1242(39) & 1641(53) \\ \text { Outpatients } & 557(26) & 373(32) \\ \text { Inpatients } & 685(49) & 1268(60)\end{array}$

Influenza $\mathbf{A}(\mathrm{H} 1 \mathrm{~N} 1)$ pdm09

$\begin{array}{ccc}\text { All patients } & 500(33) & 1641(53) \\ \text { Outpatients } & 196(22) & 373(32) \\ \text { Inpatients } & 304(40) & 1268(60) \\ \text { Influenza A(H3N2) } & & \\ \text { All patients } & 474(45) & 1641(53) \\ \text { Outpatients } & 228(33) & 373(32) \\ \text { Inpatients } & 246(57) & 1268(60) \\ \text { Influenza B } & & \\ \text { All patients } & 264(36) & 1641(53) \\ \text { Outpatients } & 134(21) & 373(32) \\ \text { Inpatients } & 130(52) & 1268(60)\end{array}$

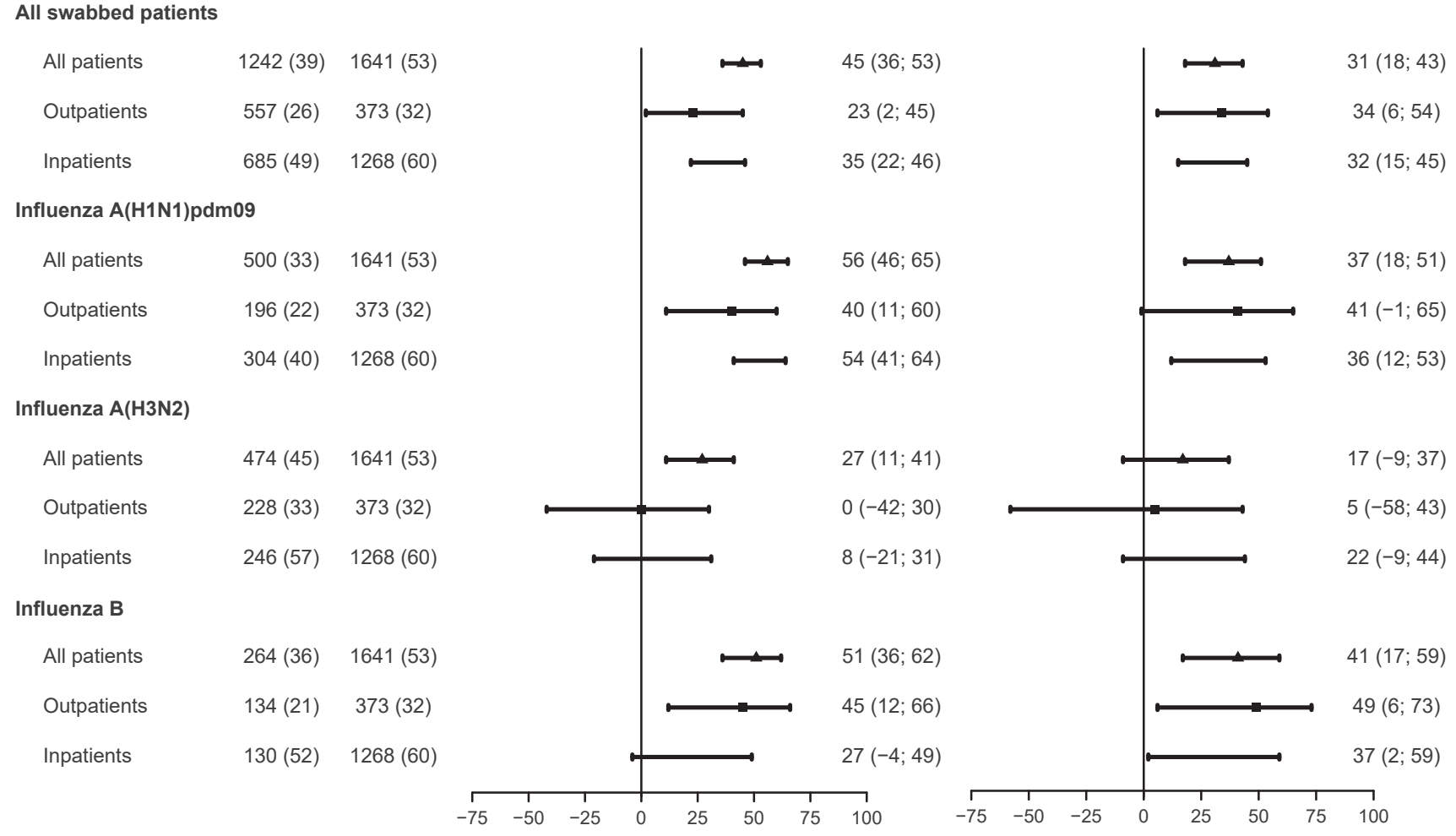

Adjusted vaccine effectiveness, $\%$ $(95 \% \mathrm{Cl})$

$\mathrm{Cl}$ : confidence interval.

Vaccine effectiveness adjusted by age groups (50-59, 60-69, 70-79 and $\geq 80$ years), sex, major chronic conditions, functional dependence, hospitalisation in the previous 12 months, healthcare setting (primary healthcare and hospital), and influenza season and month of sample collection.

VE in reducing the risk of hospital admission in people in whom the vaccine failed to prevent influenza infection.

\section{Results}

\section{Description of cases and controls}

During the six influenza seasons studied, 930 ILI patients attended primary healthcare and 1,953 ILI hospitalised patients were swabbed, and 557 (60\%) and 685 (35\%) were confirmed for influenza virus, respectively. Three virus (sub)types were widely represented: influenza $A\left(\mathrm{H}_{1} \mathrm{~N}_{1}\right)$ pdmog $(n=500$ cases; 40\%), influenza $A\left(\mathrm{H}_{3} \mathrm{~N}_{2}\right)(n=474 ; 38 \%)$ and influenza $B(n=264$; $21 \%)$. Nine patients were coinfected with two viruses. The proportion of influenza $A\left(\mathrm{H}_{1} \mathrm{~N}_{1}\right)$ pdmog virus infections was higher among inpatient than outpatient cases (44\% (303/685) vs 34\% (194/557); $p=0.001)$, while the proportion of influenza $\mathrm{A}\left(\mathrm{H}_{3} \mathrm{~N}_{2}\right)$ virus infections $(36 \%$ $(245 / 685)$ vs $41 \%(226 / 557) ; p=0.070)$ and influenza $B$ $(19 \%(125 / 685)$ vs $24 \%(133 / 557) ; p=0.030)$ was lower among inpatients.
Among primary healthcare patients, cases and controls did not differ statistically in the distribution of the analysed covariables. However, in hospitalised patients, the percentage of those aged 80 years or older and of those hospitalised in the previous 12 months was higher among controls than in cases (Table 1 ).

Compared with outpatient cases, hospitalised cases were more frequently aged 70 years or older $(61 \%$ (418/685) vs 17\% (93/557); $p<0.0001)$, had major chronic conditions ( $82 \%$ (562/685) vs 40\% (221/557); $\mathrm{p}<0.0001)$, and had a history of hospitalisation in the previous 12 months (28\% (190/685) vs 8\% (44/557), $p<0.0001)$.

None of the patients included in the study had received antiviral treatment before swabbing or hospitalisation.

\section{Influenza vaccine effectiveness by influenza season}

The influenza VE was moderate to high ( $37 \%$ to $71 \%$ ) in preventing laboratory-confirmed influenza in the seasons 2010/11 and 2015/16, both characterised by 
TABLE 1

Characteristics of laboratory-confirmed influenza cases and test-negative controls in northern Spain, 2010/11 to 2015/16

\begin{tabular}{|c|c|c|c|c|c|c|c|c|c|c|c|c|c|c|c|}
\hline & \multicolumn{2}{|c|}{$\begin{array}{c}\text { All laboratory-confirmed } \\
\text { influenza cases }\end{array}$} & \multicolumn{3}{|c|}{$\begin{array}{l}\text { All test-negative } \\
\text { controls }\end{array}$} & \multicolumn{2}{|c|}{$\begin{array}{l}\text { Outpatient } \\
\text { cases }\end{array}$} & \multicolumn{3}{|c|}{$\begin{array}{l}\text { Outpatient } \\
\text { controls }\end{array}$} & \multicolumn{2}{|c|}{$\begin{array}{l}\text { Inpatient } \\
\text { cases }\end{array}$} & \multicolumn{3}{|c|}{ Inpatient controls } \\
\hline & $\mathrm{n}$ & $\%$ & $\mathrm{n}$ & (\%) & $\mathrm{p}$ valuea & $\mathrm{n}$ & $\%$ & $\mathrm{n}$ & $\%$ & \begin{tabular}{|c|}
$p$ \\
valuea
\end{tabular} & $\mathrm{n}$ & $\%$ & $\mathrm{n}$ & $\%$ & $\begin{array}{c}p \\
\text { valuea }\end{array}$ \\
\hline \multicolumn{16}{|c|}{ Age groups (years) } \\
\hline $50-59$ & 412 & 33 & 354 & 22 & \multirow{4}{*}{$<0.001$} & 291 & 52 & 182 & 49 & \multirow{4}{*}{0.148} & 121 & 18 & 172 & 14 & \multirow{4}{*}{0.023} \\
\hline $60-69$ & 318 & 26 & 353 & 22 & & 173 & 31 & 106 & 28 & & 145 & 21 & 247 & 20 & \\
\hline $70-79$ & 268 & 22 & 419 & 26 & & 81 & 15 & 72 & 19 & & 187 & 27 & 347 & 27 & \\
\hline$\geq 80$ & 244 & 20 & 515 & 32 & & 12 & 2 & 13 & 4 & & 232 & 34 & 502 & 40 & \\
\hline \multicolumn{16}{|l|}{ Sex } \\
\hline Male & 622 & 50 & 866 & 53 & \multirow{2}{*}{0.152} & 258 & 46 & 175 & 47 & \multirow{2}{*}{0.838} & 364 & 53 & 691 & 54 & \multirow{2}{*}{0.589} \\
\hline Female & 620 & 50 & 775 & 47 & & 299 & 54 & 198 & 53 & & 321 & 47 & 577 & 46 & \\
\hline \multicolumn{16}{|c|}{ Major chronic conditions } \\
\hline No & 459 & 37 & 414 & 25 & \multirow{2}{*}{$<0.001$} & 336 & 60 & 203 & 54 & \multirow{2}{*}{0.079} & 123 & 18 & 211 & 17 & \multirow{2}{*}{0.453} \\
\hline Yes & 783 & 63 & 1,227 & 75 & & 221 & 40 & 170 & 46 & & 562 & 82 & 1,057 & 83 & \\
\hline \multicolumn{16}{|c|}{ Hospitalisation in the previous 12 months } \\
\hline No & 1,008 & 81 & 1,131 & 69 & \multirow{2}{*}{$<0.001$} & 513 & 92 & 348 & 93 & \multirow{2}{*}{0.440} & 495 & 72 & 783 & 62 & \multirow{2}{*}{$<0.001$} \\
\hline Yes & 234 & 19 & 510 & 31 & & 44 & 8 & 25 & 7 & & 190 & 28 & 485 & 38 & \\
\hline \multicolumn{16}{|c|}{ Functional dependence } \\
\hline No & 1,210 & 97 & 1,589 & 97 & \multirow{2}{*}{0.349} & 557 & 100 & 373 & 100 & \multirow{2}{*}{ NA } & 653 & 95 & 1,216 & 96 & \multirow{2}{*}{0.549} \\
\hline Yes & 32 & 3 & 52 & 3 & & 0 & 0 & 0 & 0 & & 32 & 5 & 52 & 4 & \\
\hline Influenza vacc & e status & & & & & & & & & & & & & & \\
\hline Unvaccinated & 764 & 61 & 766 & 47 & & 412 & 74 & 252 & 68 & & 352 & 51 & 514 & 40 & \\
\hline Vaccinated & 478 & 39 & 875 & 53 & $<0.001$ & 145 & 26 & 121 & 32 & 0.033 & 333 & 49 & 754 & 60 & $<0.001$ \\
\hline Influenza seas & & & & & & & & & & & & & & & \\
\hline $2010 / 11$ & 100 & 8 & 237 & 14 & & 50 & 9 & 55 & 15 & & 50 & 7 & 182 & 14 & \\
\hline $2011 / 12$ & 129 & 10 & 116 & 7 & & 112 & 20 & 62 & 17 & & 17 & 3 & 54 & 4 & \\
\hline $2012 / 13$ & 90 & 7 & 131 & 8 & & 66 & 12 & 52 & 14 & 0.061 & 24 & 4 & 79 & 6 & $<0.001$ \\
\hline $2013 / 14$ & 279 & 23 & 314 & 19 & 0.001 & 93 & 17 & 53 & 14 & 0.061 & 186 & 27 & 261 & 21 & 8.001 \\
\hline $2014 / 15$ & 279 & 23 & 313 & 19 & & 114 & 21 & 67 & 18 & & 165 & 24 & 246 & 19 & \\
\hline $2015 / 16$ & 365 & 29 & 530 & 32 & & 122 & 22 & 84 & 23 & & 243 & 36 & 446 & 35 & \\
\hline Total & 1,242 & 100 & 1,641 & 100 & & 557 & 100 & 373 & 100 & & 685 & 100 & 1,268 & 100 & \\
\hline
\end{tabular}

NA: not applicable.

a Chi-squared test.

a predominance of influenza $\mathrm{A}\left(\mathrm{H}_{1} \mathrm{~N}_{1}\right)$ pdmog virus, as well as in the $2012 / 13$ season dominated by influenza B. However, the VE was low to moderate ( $2 \%$ to $53 \%$ ) in the $2011 / 12,2013 / 14$ and $2014 / 15$ seasons, when the influenza $\mathrm{A}\left(\mathrm{H}_{3} \mathrm{~N}_{2}\right)$ virus circulated widely. In the $2013 / 14$ and $2014 / 15$ seasons the estimates of influenza VE were null in preventing outpatient cases and were somewhat higher in inpatient cases. In three influenza seasons (2010/11, 2011/12 and 2015/16) the point estimate of VE was higher in outpatients, and in other three seasons (2012/13, 2013/14 and 2014/15), it was higher among inpatients (Table 2 ).

\section{Average effectiveness of the influenza vaccine in six seasons}

In the analysis of the six influenza seasons, the laboratory-confirmed cases had received the influenza vaccine in a lower proportion (39\%) than the test-negative controls ( $53 \%$; $p<0.001)$. In the adjusted analysis, the average VE was 34\% (95\% Cl: 6 to 54 ) in preventing outpatient cases and $32 \%(95 \% \mathrm{Cl}: 15$ to 45$)$ in preventing hospitalised cases (Table 3 and Figure).

$V E$ in preventing laboratory-confirmed influenza $\mathrm{A}\left(\mathrm{H}_{1} \mathrm{~N}_{1}\right)$ pdmog was $41 \%$ ( $95 \% \mathrm{Cl}:-1$ to 65$)$ for outpatient cases and $36 \%(95 \% \mathrm{Cl}: 12$ to 53$)$ for hospitalised 
TABLE 2

Influenza vaccine effectiveness in preventing laboratory-confirmed cases by season and healthcare setting in northern Spain, 2010/11 to $2015 / 16$

\begin{tabular}{|c|c|c|c|c|c|c|}
\hline & $2010 / 11$ & $2011 / 12$ & $2012 / 13$ & $2013 / 14$ & $2014 / 15$ & $2015 / 16$ \\
\hline \multicolumn{7}{|l|}{ All patients } \\
\hline Cases, n (\% vaccinated) & $100(27)$ & $129(29)$ & $90(19)$ & $279(45)$ & $279(47)$ & $365(38)$ \\
\hline Influenza A(H1N1)pdmo9 & 95 & 0 & 22 & 95 & 6 & 279 \\
\hline Influenza $\mathrm{A}\left(\mathrm{H}_{3} \mathrm{~N}_{2}\right)$ & 0 & 117 & 6 & 177 & 137 & 34 \\
\hline Influenza B & 5 & 12 & 62 & o & 133 & 46 \\
\hline Controls, $\mathrm{n}$ (\% vaccinated) & $237(52)$ & $116(41)$ & $131(47)$ & $314(56)$ & $313(53)$ & $530(57)$ \\
\hline Crude VE, \% $(95 \% \mathrm{Cl})$ & 66 (43 to 79) & $43(3$ to 66$)$ & $73(50$ to 86$)$ & 35 (9 to 53$)$ & $21(-10$ to 42$)$ & $53(39$ to 64$)$ \\
\hline Adjusted VE, \% $(95 \% \mathrm{Cl})^{\text {a }}$ & $53(14$ to 74$)$ & $53(-9$ to 79$)$ & $71(35$ to 87$)$ & $21(-15$ to 46$)$ & $2(-44$ to 33$)$ & 37 (14 to 55$)$ \\
\hline \multicolumn{7}{|l|}{ Outpatients } \\
\hline Cases, n (\% vaccinated) & $50(14)$ & $112(26)$ & $66(14)$ & $93(38)$ & $114(32)$ & $122(24)$ \\
\hline Influenza A(H1N1)pdmo9 & 47 & 0 & 16 & 31 & 3 & 97 \\
\hline Influenza $\mathrm{A}\left(\mathrm{H}_{3} \mathrm{~N}_{2}\right)$ & 0 & 102 & 3 & 60 & 49 & 12 \\
\hline Influenza B & 3 & 10 & 47 & o & 62 & 11 \\
\hline Controls, $\mathrm{n}$ (\% vaccinated) & $55(31)$ & $62(32)$ & $52(33)$ & $53(32)$ & $67(25)$ & $84(39)$ \\
\hline Crude VE, \% $(95 \% \mathrm{Cl})$ & 64 (3 to 86$)$ & $27(-45$ to 63$)$ & $67(19$ to 87$)$ & $\begin{array}{c}-26(-156 \text { to } \\
38) \\
\end{array}$ & $\begin{array}{c}-36(-167 \text { to } \\
31) \\
\end{array}$ & $52(12$ to 74$)$ \\
\hline Adjusted VE, \% $(95 \% \mathrm{Cl})^{\text {a }}$ & $84(34$ to 95$)$ & $58(-20$ to 85$)$ & 78 (4 to 89$)$ & $\begin{array}{c}-35(-231 \text { to } \\
45)\end{array}$ & $\begin{array}{c}-66(-280 \text { to } \\
27)\end{array}$ & $45(-14$ to 74$)$ \\
\hline \multicolumn{7}{|l|}{ Inpatients } \\
\hline Cases, n (\% vaccinated) & $50(40)$ & $17(47)$ & $24(33)$ & $186(49)$ & $165(58)$ & $243(46)$ \\
\hline Influenza A(H1N1)pdmo9 & 48 & 0 & 6 & 64 & 3 & 182 \\
\hline Influenza $\mathrm{A}\left(\mathrm{H}_{3} \mathrm{~N}_{2}\right)$ & 0 & 15 & 3 & 117 & 88 & 22 \\
\hline Influenza B & 2 & 2 & 15 & 0 & 71 & 35 \\
\hline Controls, $\mathrm{n}$ (\% vaccinated) & $182(58)$ & $54(52)$ & $79(56)$ & $261(61)$ & $246(60)$ & $446(61)$ \\
\hline Crude VE, \% $(95 \% \mathrm{Cl})$ & $52(9$ to 75$)$ & $17(-146$ to 72$)$ & $60(-4$ to 85$)$ & $37(8$ to 57$)$ & $10(-34$ to 40$)$ & $45(25$ to 60$)$ \\
\hline Adjusted VE, \% $(95 \% \mathrm{Cl})^{\text {a }}$ & $36(-32$ to 68$)$ & $-4(-485$ to 82$)$ & 81 (28 to 95$)$ & $32(-5$ to 56$)$ & $16(-31$ to 46$)$ & $36(8$ to 56$)$ \\
\hline
\end{tabular}

$\mathrm{Cl}$ : confidence interval; VE: vaccine effectiveness.

a Vaccine effectiveness adjusted by age groups (50-59, 60-69, 70-79 and $\geq 80$ years), sex, major chronic conditions, functional dependence, hospitalisation in the previous 12 months, healthcare setting (primary healthcare and hospital), and month of sample collection.

cases, and was $49 \%(95 \% \mathrm{Cl}: 6$ to 73$)$ and $37 \%(95 \%$ $\mathrm{Cl}: 2$ to 59), respectively, to prevent influenza $\mathrm{B}$. Nevertheless, a low and non-significant effect was observed for the prevention of outpatient and inpatient cases of influenza $A\left(\mathrm{H}_{3} \mathrm{~N}_{2}\right)$ (Figure).

The adjusted VE estimates did not show relevant differences by pre-existing comorbidity. Although the interaction terms did not reach statistical significance, the adjusted VE estimate seemed to be lower in outpatients aged 65 years or older than in those aged $50-64$ years ( $3 \%$ vs $56 \%$; $p=0.064$ ), but this difference nearly disappeared in hospitalised cases ( $29 \%$ vs $43 \% ; p=0.524$ ) (Table 3).

In the analysis of the general practice setting, adults aged 65 years or older had lower adjusted VE than those aged $50-64$ years against influenza $A\left(\mathrm{H}_{3} \mathrm{~N}_{2}\right)$ $(-48 \%$ vs $40 \% ; p=0.155)$ and influenza $A\left(\mathrm{H}_{1} \mathrm{~N}_{1}\right)$ pdmog ( $-20 \%$ vs $63 \% ; p=0.068)$, although both comparisons did not reach statistical significance. A similar difference was not observed in influenza B (62\% vs 55\%; $p=0.892$ ). In the analysis of hospitalised patients such declines in VE with age were not observed (Table 4).

\section{Comparison of vaccine effectiveness between outpatient and inpatient cases}

In the analysis of all influenza cases, a non-statistically significant decrease in the risk of hospitalisation among vaccinated cases was observed (adjusted OR $0.83 ; 95 \% \mathrm{Cl}: 0.59$ to 1.18 ). Influenza vaccination was associated with a $54 \%$ reduction in hospitalisation among influenza $\mathrm{A}\left(\mathrm{H}_{3} \mathrm{~N}_{2}\right)$ cases (adjusted $\mathrm{OR} 0.46$; $95 \% \mathrm{Cl}: 0.24$ to 0.90 ). Although other results did not reach statistical significance, influenza vaccination seemed to be associated with a decline in the risk of hospitalisation among influenza $\mathrm{A}\left(\mathrm{H}_{1} \mathrm{~N}_{1}\right)$ pdmog cases (adjusted OR $0.73 ; 95 \% \mathrm{Cl}: 0.42$ to 1.27 ) and with an increase in hospital admissions among influenza $B$ cases (adjusted OR 1.64; 95\% Cl: 0.75 to 3.59). The analyses stratified in two age groups were consistent for influenza $A\left(\mathrm{H}_{3} \mathrm{~N}_{2}\right)$; and, although non-statistically significant, the point estimates suggest a decline in the risk of hospitalisation of influenza $A\left(\mathrm{H}_{1} \mathrm{~N}_{1}\right)$ pdmog 
TABLE 3

Influenza vaccine effectiveness in preventing laboratory-confirmed cases by healthcare setting, age and comorbidity in northern Spain, 2010/11 to 2015/16

\begin{tabular}{|c|c|c|c|}
\hline & All patients & Outpatients & Inpatients \\
\hline \multicolumn{4}{|l|}{ All swabbed patients } \\
\hline Cases, n (\% vaccinated) & $1,242(39)$ & $557(26)$ & $685(49)$ \\
\hline Controls, n (\% vaccinated) & $1,641(53)$ & $373(32)$ & $1,268(60)$ \\
\hline Crude VE, \% (95\% Cl) & $45(36$ to 53$)$ & 23 (2 to 45$)$ & $35(22$ to 46$)$ \\
\hline Adjusted VE, \% $(95 \% \mathrm{Cl})^{a}$ & $31(18$ to 43$)$ & $34(6$ to 54$)$ & $32(15$ to 45$)$ \\
\hline \multicolumn{4}{|l|}{ Aged $50-64$ years old } \\
\hline Cases, n (\% vaccinated) & $572(16)$ & $384(13)$ & $188(21)$ \\
\hline Controls, n (\% vaccinated) & $523(27)$ & $242(20)$ & $281(32)$ \\
\hline Crude VE, \% (95\% Cl) & 49 (31 to 62) & 41 (9 to 62$)$ & $44(14$ to 34$)$ \\
\hline Adjusted VE, \% $(95 \% \mathrm{Cl})^{\text {a }}$ & $49(29$ to 64$)$ & $56(29$ to 73$)$ & $43(5$ to 66$)$ \\
\hline \multicolumn{4}{|l|}{ Aged $\geq 65$ years old } \\
\hline Cases, n (\% vaccinated) & $670(58)$ & $173(55)$ & 497 (59) \\
\hline Controls, n (\% vaccinated) & $1,118(66)$ & $131(55)$ & $987(67)$ \\
\hline Crude VE, \% $(95 \% \mathrm{Cl})$ & $28(12$ to 41$)$ & $1(-55$ to 37$)$ & $29(11$ to 43$)$ \\
\hline Adjusted VE, \% $(95 \% \mathrm{Cl})^{a}$ & $25(6$ to 40$)$ & $3(-71$ to 45$)$ & 29 (9 to 44$)$ \\
\hline \multicolumn{4}{|c|}{ Patients without major chronic conditions } \\
\hline Cases, $\mathrm{n}$ (\% vaccinated) & $459(22)$ & $336(20)$ & $123(28)$ \\
\hline Controls, n (\% vaccinated) & $414(29)$ & $203(20)$ & $211(37)$ \\
\hline Crude VE, \% $(95 \% \mathrm{Cl})$ & $31(6$ to 49$)$ & $3(-49$ to 37$)$ & $35(-6$ to 60$)$ \\
\hline Adjusted VE, \% $(95 \% \mathrm{Cl})^{\text {a }}$ & $32(-1$ to 54$)$ & $23(-31$ to 55$)$ & $42(-15$ to 71$)$ \\
\hline \multicolumn{4}{|c|}{ Patients with major chronic conditions } \\
\hline Cases, $\mathrm{n}$ (\% vaccinated) & $783(48)$ & $221(36)$ & $562(53)$ \\
\hline Controls, $\mathrm{n}$ (\% vaccinated) & $1,227(62)$ & $170(47)$ & $1,057(64)$ \\
\hline Crude VE, \% $(95 \% \mathrm{Cl})$ & $42(30$ to 51$)$ & 38 (7 to 59 ) & $36(21$ to 48$)$ \\
\hline Adjusted VE, \% $(95 \% \mathrm{Cl})^{\text {a }}$ & $32(16$ to 45$)$ & $41(2$ to 65$)$ & $30(12$ to 45$)$ \\
\hline
\end{tabular}

$\mathrm{Cl}$ : confidence interval; VE: vaccine effectiveness.

a Vaccine effectiveness adjusted by age groups (50-59, 60-69, 70-79 and $\geq 80$ years), sex, major chronic conditions, functional dependence, hospitalisation in the previous 12 months, healthcare setting (primary healthcare and hospital), and influenza season and month of sample collection.

cases aged 65 years or older. In the 2013/14 season dominated by influenza $A\left(\mathrm{H}_{3} \mathrm{~N}_{2}\right)$ virus, influenza vaccination was also associated with lower risk of hospitalisation among influenza cases (adjusted OR 0.49; 95\% $\mathrm{Cl}: 0.24$ to 0.99 ) (Table 5).

The comparison of hospitalised controls vs outpatient controls did not find an association with vaccine status in the adjusted analysis (adjusted OR 1.01; 95\% $\mathrm{Cl}: 0.72$ to 1.41 ), thus indicating successful control of potential confounding.

\section{Discussion}

During six influenza seasons from 2010/11 to 2015/16, the trivalent inactivated influenza VE was on average moderate and similar in preventing laboratory-confirmed influenza in general practice (34\%) and hospital settings $(32 \%)$, with both outcomes evaluated at the same time and in the same population of older adults. VE was moderate against cases of influenza $A\left(\mathrm{H}_{1} \mathrm{~N}_{1}\right)$ pdmo9 (37\%) and influenza B (41\%), and was low against cases infected with Influenza $A\left(\mathrm{H}_{3} \mathrm{~N}_{2}\right)$ virus
(17\%). These results are consistent with the results of a recent systematic review [28].

In the majority of situations evaluated in our study, the same type and brand of influenza vaccine in the same season was equally effective in preventing laboratoryconfirmed influenza cases that required outpatient assistance and those requiring hospitalisation. These results confirm those of a Spanish multicentre study that compared VE in outpatient and inpatient settings in the same areas in a single influenza season [8], as well as the analysis of 25 pairs of VE estimates from parallel studies in inpatient and outpatient settings in the same influenza season, in the same country, and in similar age groups, although only three of these pairs covered both settings in the same population [10]. Our results are also consistent with the absence of association between influenza vaccination and hospital admissions within 14 days after illness onset reported among outpatient cases with laboratory-confirmed influenza [29]. All this evidence argues against the hypothesis that, in general, influenza vaccination 
Influenza vaccine effectiveness in preventing laboratory-confirmed cases by healthcare setting, age group and virus (sub) type, northern Spain, 2010/11 to 2015/16

\begin{tabular}{|c|c|c|c|c|c|c|}
\hline & \multicolumn{3}{|c|}{ Age $50-64$ years } & \multicolumn{3}{|c|}{ Age $\geq 65$ years } \\
\hline & All patients & Outpatients & Inpatients & All patients & Outpatients & Inpatients \\
\hline \multicolumn{7}{|l|}{ Influenza A(H1N1)pdmog } \\
\hline Cases, n (\% vaccinated) & $273(15)$ & $148(12)$ & 125 (19) & $227(55)$ & $48(56)$ & $179(55)$ \\
\hline Controls, $\mathrm{n}$ (\% vaccinated) & $523(27)$ & $242(20)$ & $281(32)$ & $1,118(66)$ & $131(55)$ & $987(67)$ \\
\hline Crude VE, \% $(95 \% \mathrm{Cl})$ & $51(28$ to 67$)$ & 49 (7 to 72$)$ & $50(16$ to 70$)$ & $36(15$ to 52$)$ & $-1(-95$ to 48$)$ & $40(18$ to 57$)$ \\
\hline Adjusted VE, \% $(95 \% \mathrm{Cl})^{\text {a }}$ & 56 (31 to 72$)$ & $63(26$ to 82$)$ & 47 (2 to 72$)$ & $25(-6$ to 46$)$ & $-20(-200$ to 52$)$ & 31 (1 to 52$)$ \\
\hline \multicolumn{7}{|l|}{ Influenza $\mathrm{A}\left(\mathrm{H}_{3} \mathrm{~N}_{2}\right)$} \\
\hline Cases, n (\% vaccinated) & $175(17)$ & $138(15)$ & $37(24)$ & $299(62)$ & $90(59)$ & $209(63)$ \\
\hline Controls, $\mathrm{n}$ (\% vaccinated) & $523(27)$ & $242(20)$ & $281(32)$ & $1118(66)$ & $131(55)$ & $987(67)$ \\
\hline Crude VE, \% $(95 \% \mathrm{Cl})$ & $43(11$ to 63$)$ & $31(-24$ to 60$)$ & $32(-51$ to 69$)$ & $16(-10$ to 35$)$ & $-17(-102$ to 32$)$ & $17(-14$ to 39$)$ \\
\hline Adjusted VE, \% $(95 \% \mathrm{Cl})^{\text {a }}$ & $36(-12$ to 63$)$ & $40(-23$ to 70$)$ & $39(-71$ to 78$)$ & $14(-19$ to 38$)$ & $-48(-249$ to 38$)$ & $21(-12$ to 45$)$ \\
\hline \multicolumn{7}{|l|}{ Influenza B } \\
\hline Cases, n (\% vaccinated) & $124(15)$ & $98(12)$ & $26(23)$ & $140(55)$ & $36(44)$ & $104(59)$ \\
\hline Controls, $\mathrm{n}$ (\% vaccinated) & $523(27)$ & $242(20)$ & $281(32)$ & $1118(66)$ & $131(55)$ & $987(67)$ \\
\hline Crude VE, \% $(95 \% \mathrm{Cl})$ & $53(20$ to 73$)$ & $45(-9$ to 72$)$ & $36(-64$ to 75$)$ & 37 (9 to 55 ) & $34(-38$ to 69$)$ & $31(-4$ to 54$)$ \\
\hline Adjusted VE, \% $(95 \% \mathrm{Cl})^{\text {a }}$ & $47(-2$ to 73$)$ & $55(-9$ to 81$)$ & $13(-184$ to 73$)$ & 41 (10 to 61$)$ & $62(-7$ to 87$)$ & 40 (3 to 63$)$ \\
\hline
\end{tabular}

$\mathrm{Cl}$ : confidence interval; VE: vaccine effectiveness.

a Vaccine effectiveness adjusted by age groups 50-59, 60-69, 70-79 and $\geq 80$ years), sex, major chronic conditions, functional dependence, hospitalisation in the previous 12 months, healthcare setting (primary healthcare and hospital), and influenza season and month of sample collection.

mitigates influenza illness severity and reduces the risk of hospital admission in people in whom it did not prevent influenza infection.

Nevertheless, in some analyses we observed a different behaviour. The vaccine was not effective in preventing outpatient cases of influenza $A\left(\mathrm{H}_{3} \mathrm{~N}_{2}\right)$, but did provide some protection (22\%) against hospitalisations. This difference in VE was demonstrated in the case-to-case comparison and was also observed in the specific analysis of the $2013 / 14$ season when $A\left(\mathrm{H}_{3} \mathrm{~N}_{2}\right)$ virus predominated and VE was very low. A higher protection of the vaccine against hospitalisations was also suggested in the analysis of influenza $A\left(\mathrm{H}_{1} \mathrm{~N}_{1}\right)$ pdmog cases aged 65 years or older.

Recently, Petrie et al. [30] reported higher VE in preventing hospitalisations than that reported from similar studies in ambulatory care settings, in a season with circulating influenza $\mathrm{A}\left(\mathrm{H}_{3} \mathrm{~N}_{2}\right)$ viruses that were antigenically drifted from the vaccine virus. In our study the higher VE among hospitalised influenza cases was associated with very low or no VE, type A influenza virus, and older patients. In situations of low vaccine-induced immunity against the circulating viruses, the relative importance of the vaccine effect in mitigating the severity of illness in vaccine failures would increase. This additional benefit of the vaccine cannot be detected in studies based on general practice settings only.
The average effect of the vaccine over all six seasons seemed to be lower in adults aged 65 or older than in those aged 50-64 years, which could be explained by immunosenescence [11]. Interestingly, this reduced VE with increasing age was pronounced in outpatient cases with influenza type $A$, but was hardly seen in inpatient cases or in cases of influenza B. This finding has a positive component since this loss of VE with age would be smaller in more severe forms of influenza. All these results suggest that, even though on average influenza VE is similar in both healthcare settings, in some situations involving influenza A virus infections, elderly patients and low VE, there may be important differences in VE between patients in outpatient and inpatient settings, that can also be interpreted as an additional vaccine effect that reduces the risk of hospital admission in people in whom the vaccine fails to prevent influenza infection.

The joint analysis of primary healthcare patients and hospitalised patients recruited in the same season and region shows the effect of the vaccine on a more complete clinical spectrum of the disease, including mild, moderate and severe cases, and on a more varied patient profile. The absence of differences in vaccination status in the adjusted analysis of outpatient and inpatient controls reduces the difficulties in interpreting joint estimations of VE.

This study has several strengths. We used the testnegative design nested in a population-based cohort in both the general practice and hospital settings, which 
TABLE 5

Comparison of the influenza vaccination status of inpatient vs outpatient influenza cases by influenza (sub)type, age group and season, northern Spain, 2010/11 to 2015/16

\begin{tabular}{|c|c|c|c|c|c|c|}
\hline & \multicolumn{2}{|c|}{ Inpatient cases } & \multicolumn{2}{|c|}{ Outpatient cases } & \multirow[t]{2}{*}{ AOR $(95 \% \mathrm{Cl})^{\mathrm{a}}$} & \multirow[t]{2}{*}{$p$ value } \\
\hline All ages and seasons & $\mathrm{n}$ & $\%$ vaccinated & $\mathrm{n}$ & $\%$ vaccinated & & \\
\hline Total & 685 & 49 & 557 & 26 & $0.83(0.59$ to 1.18$)$ & 0.304 \\
\hline Influenza A(H1N1)pdmog & 304 & 40 & 196 & 22 & $0.73(0.42$ to 1.27$)$ & 0.268 \\
\hline Influenza $\mathrm{A}\left(\mathrm{H}_{3} \mathrm{~N}_{2}\right)$ & 246 & 57 & 228 & 33 & $0.46(0.24$ to 0.90$)$ & 0.023 \\
\hline Influenza B & 130 & 52 & 134 & 21 & 1.64 (0.75 to 3.59) & 0.215 \\
\hline \multicolumn{7}{|l|}{ Age $50-64$ years } \\
\hline Total & 188 & 21 & 384 & 13 & $1.03(0.59$ to 1.80$)$ & 0.919 \\
\hline Influenza A(H1N1)pdmog & 125 & 19 & 148 & 12 & 1.17 (0.53 to 2.58$)$ & 0.698 \\
\hline Influenza $\mathrm{A}\left(\mathrm{H}_{3} \mathrm{~N}_{2}\right)$ & 37 & 24 & 138 & 15 & $0.32(0.09$ to 1.23$)$ & 0.099 \\
\hline Influenza B & 26 & 23 & 98 & 12 & $2.36(0.59$ to 9.45$)$ & 0.227 \\
\hline \multicolumn{7}{|l|}{ Age $\geq 65$ years } \\
\hline Total & 497 & 59 & 173 & 55 & $0.71(0.44$ to 1.14$)$ & 0.156 \\
\hline Influenza A(H1N1)pdmog & 179 & 55 & 48 & 56 & $0.41(0.16$ to 1.03$)$ & 0.056 \\
\hline Influenza $\mathrm{A}\left(\mathrm{H}_{3} \mathrm{~N}_{2}\right)$ & 209 & 63 & 90 & 59 & $0.50(0.22$ to 1.12$)$ & 0.092 \\
\hline Influenza B & 104 & 59 & 36 & 44 & 1.81 (0.63 to 5.17$)$ & 0.269 \\
\hline \multicolumn{7}{|l|}{ Influenza season } \\
\hline $2010 / 11$ & 50 & 40 & 50 & 14 & $3.03(0.83$ to 11.12$)$ & 0.095 \\
\hline $2011 / 12$ & 17 & 47 & 112 & 26 & $0.40(0.09$ to 1.88$)$ & 0.245 \\
\hline $2012 / 13$ & 24 & 33 & 66 & 14 & 1.17 (0.15 to 8.95) & 0.877 \\
\hline $2013 / 14$ & 186 & 49 & 93 & 38 & 0.49 (0.24 to 0.99$)$ & 0.048 \\
\hline $2014 / 15$ & 165 & 58 & 114 & 32 & $0.91(0.45$ to 1.83$)$ & 0.797 \\
\hline $2015 / 16$ & 243 & 46 & 122 & 24 & $0.87(0.45$ to 1.67$)$ & 0.668 \\
\hline
\end{tabular}

AOR: adjusted odds ratio; $\mathrm{Cl}$ : confidence interval.

${ }^{a}$ OR and $95 \% \mathrm{Cl}$ adjusted by age groups (50-59, 60-69, 70-79 and $\geq 80$ years), sex, major chronic conditions, functional dependence, hospitalisation in the previous 12 months, and influenza season and month of sample collection.

allows evaluation and comparison of VE against outpatient and inpatient influenza cases. All cases were laboratory-confirmed, and the controls tested negative for influenza. The outpatient and hospitalised patients were recruited in the same population and in the same influenza seasons, received the same type and brand of vaccine, and were exposed to the same circulating viruses. To compare VE in both settings we directly compared the vaccination status of inpatient cases vs outpatient cases, which eliminates possible problems of comparability between the two control groups and, interestingly, reveals the vaccine effect in preventing hospitalisations among laboratory-confirmed influenza cases [8]. The analysis of six seasons increased the power of the study and achieved sufficient representation of different virus (sub)types and patient characteristics. The variability due to vaccine type was minimal since only one product was used in the vaccination programme in each season.

This study had some possible limitations. Although restriction to adults above 50 years of age considerably improved the comparability between outpatient and inpatient cases, there nevertheless remained differences that could hamper sufficient control of confounding factors. Moreover, we cannot totally discount the 'healthy vaccinee effect' whereby frail patients may be less likely to be vaccinated and more likely to be admitted to hospital [31]. However, this does not seem to have occurred since the adjusted model that compared inpatient controls with outpatient controls did not find an association between vaccination status and healthcare setting. We included adults aged 50-59 years, in whom vaccination is recommended and offered free of charge only if they have a chronic condition; however, all analyses were adjusted or stratified by age, and this did not seem to have an important effect on the results.

Estimates in hospitalised patients may be biased if they are diagnosed with a longer delay from the time of infection; however, in our study this bias was reduced as access to hospital emergency rooms was unrestricted, admission was based only on medical judgment, and there was a protocol for early swabbing and testing of ILI cases before admission.

Hospitalised cases were older and had more comorbidities than outpatient cases, and this may increase the risk of false negative results due to reduced viral shedding with age [32]. We reduced this bias by double swabbing of patients, restricting the analysis to older 
adults, and adjusting by age groups in the case-tocase comparison.

Although we analysed six influenza seasons and the number of patients included was high, the statistical power in some analyses (by season or age subgroup) was low; therefore caution should be exercised when explaining some results.

The effect of prior vaccination has arisen as a relevant factor in understanding influenza VE, but addressing this issue requires specifically focused studies [22,33]. In conclusion, influenza vaccination was on average moderately effective in preventing laboratory-confirmed influenza over six seasons in northern Spain. In general, VE was similar in preventing outpatient cases and hospitalisations with influenza, although in some situations involving influenza A virus infection, elderly patients and low vaccine effectiveness, influenza vaccination may have an additional effect in reducing the risk of hospital admission in people in whom the vaccine fails to prevent influenza infection. This effect increases the total benefit of the influenza vaccine and reinforces the recommendation of vaccination. The general practice and hospital settings provide complementary points of view for understanding the complete effect of the influenza vaccination. More studies linking both points of view are needed.

Members of the Primary Health Care Sentinel Network of Navarre

I Abad, P Aldaz, E Álvarez, N Alvarez, JJ Arana, I Arceiz, E Arina, I Arribas, MD Artajo, B Azagra, FC Bartolome, C Bolea, A Brugos, B Cano, MV Castresana, JC Cenoz, F Cia, B Compains, F Cortés, B Churío, PC Cuevas, EM Da Costa, J Díez Espino, M Doiz, FJ Escribano, MJ Esparza, V Etayo, C Fernández Alfaro, B Flamarique, J Gamboa, ML Garcés, L García Blanco, AB German, A Giner, N Goñi, MJ Guillorme, JO Guiu, JC Gurbindo, MJ Guruchaga, JA Heras, MC Hijos, J Huidobro, S Indurain, B Iñigo, MC Irigoyen, J Jurio, MP León, JJ Longás, MJ López, MT Maquirriain, JJ Miner, M Moreno, MA Moros, U Navarro, F) Orozco, M Orte, P Palacio, J Palau, C Pérez Lecumberri, P Pérez Pascual, B Pérez Sanz, A Prado, M Prado, A Puig, E Ridruejo, M Ramos, BE Rípodas, M Rodríguez, MA Roncal, I Ruiz Puertas, C Sánchez, P Sarrasqueta, MA Senosiain, J Sola, M Sota, ME Ursua, IA Urtasun, MJ Vigata, MT Virto, F Elía, E Albeniz.

Members of the Network for Influenza Surveillance in Hospitals of Navarre

P Artajo, X Beristain, J Chamorro, C Ezpeleta, P Fanlo, F Gil, J Hueto, C Martín, A Navascués, L Peña, I Polo, M Ruiz, N Viguria (Complejo Hospitalario de Navarra), M Fernández-Alonso, G Reina (Clínica Universidad de Navarra), JJ García Irure, M Ortega, M Torres (Hospital Reina Sofía, Tudela), F Lameiro, Al Álvaro (Hospital García Orcoyen, Estella), I Casado, A Zabala, M García Cenoz, J Díaz-González, L Fernandino, M Arriazu, A Barricarte, J Castilla (Instituto de Salud Pública de Navarra).
Acknowledgements

This work was supported by the Horizon 2020 program of the European Commission (agreement 634446); by the I-MOVE (Influenza Monitoring Vaccine Effectiveness in Europe) Network funded by the European Centre for Disease Prevention and Control; by La Caixa Foundation; and the Carlos III Institute of Health with the European Regional Development Fund (ERDF) (Plog/01179, Pl12/00087, CM15/00119, INT13/00013, INT14/00013, INT15/00182, INT16/00122).

\section{Conflict of interest}

None declared.

\section{Authors' contributions}

J Castilla, I Martínez-Baz, I Casado and M Guevara designed the study and coordinated the activities. I Martínez-Baz, J Delfrade and J Castilla undertook the statistical analysis. A Navascués, A Aguinaga and C Ezpeleta were responsible of the virological analysis and the interpretation of laboratory results. The members of the Primary Health Care Sentinel Network and the Network for Influenza Surveillance in Hospitals of Navarre participated in the data collection. J Castilla, I Casado and I Martínez-Baz wrote the draft manuscript, and all authors revised and approved the final version.

\section{References}

1. Glezen WP. Serious morbidity and mortality associated with influenza epidemics. Epidemiol Rev. 1982;4(1):25-44. https:// doi.org/10.1093/oxfordjournals.epirev.a036250 PMID: 6754408

2. Thompson WW, Shay DK, Weintraub E, Brammer L, Bridges CB, Cox NJ, et al. Influenza-associated hospitalizations in the United States. JAMA. 2004;292(11):1333-40. https://doi. org/10.1001/jama.292.11.1333 PMID: 15367555

3. Reed C, Chaves SS, Daily Kirley P, Emerson R, Aragon D, Hancock EB, et al. Estimating influenza disease burden from population-based surveillance data in the United States. PLoS One. 2015;10(3):e0118369. https://doi.org/10.1371/journal. pone.0118369 PMID: 25738736

4. Osterholm MT, Kelley NS, Sommer A, Belongia EA. Efficacy and effectiveness of influenza vaccines: a systematic review and meta-analysis. Lancet Infect Dis. 2012;12(1):36-44. https://doi. org/10.1016/S1473-3099(11)70295-X PMID: 22032844

5. Kissling E, Valenciano M, Buchholz U, Larrauri A, Cohen JM, Nunes B, et al. Influenza vaccine effectiveness estimates in Europe in a season with three influenza type/subtypes circulating: the I-MOVE multicentre case-control study, influenza season 2012/13. Euro Surveill. 2014;19(6):20701. https://doi.org/10.2807/1560-7917.ES2014.19.6.20701 PMID: 24556348

6. Puig-Barberà J, García-de-Lomas J, Díez-Domingo J, ArnedoPena A, Ruiz-García M, Limón-Ramírez R, et al. Influenza vaccine effectiveness in preventing influenza $A\left(\mathrm{H}_{3} \mathrm{~N}_{2}\right)$-related hospitalizations in adults targeted for vaccination by type of vaccine: a hospital-based test-negative study, 2011-2012 $\mathrm{A}\left(\mathrm{H}_{3} \mathrm{~N}_{2}\right)$ predominant influenza season, Valencia, Spain. PLoS One. 2014;9(11):e112294. https://doi.org/10.1371/journal. pone.0112294 PMID: 25392931

7. Havers F, Sokolow L, Shay DK, Farley MM, Monroe M, Meek J, et al. Case-control study of vaccine effectiveness in preventing laboratory-confirmed influenza hospitalizations in older adults, United States, 2010-11. Clin Infect Dis. 2016;63(10):1304-11. https://doi.org/10.1093/cid/ciw512 PMID: 2748611

8. Castilla J, Godoy P, Domínguez A, Martínez-Baz I, Astray J, Martín V, et al. Influenza vaccine effectiveness in preventing outpatient, inpatient, and severe cases of laboratoryconfirmed influenza. Clin Infect Dis. 2013;57(2):167-75. https:// doi.org/10.1093/cid/cit194 PMID: 23532475

9. Darvishian M, Bijlsma MJ, Hak E, van den Heuvel ER. Effectiveness of seasonal influenza vaccine in community-dwelling elderly people: a meta-analysis of test-negative design case-control studies. Lancet Infect 
Dis. 2014;14(12):1228-39. https://doi.org/10.1016/S14733099(14)70960-0 PMID: 25455990

10. Feng S, Cowling BJ, Sullivan SG. Influenza vaccine effectiveness by test-negative design - Comparison of inpatient and outpatient settings. Vaccine. 2016;34(14):1672-9. https:// doi.org/10.1016/j.vaccine.2016.02.039 PMID: 26920469

11. Reber AJ, Chirkova T, Kim JH, Cao W, Biber R, Shay DK, et al. Immunosenescence and challenges of vaccination against influenza in the aging population. Aging Dis. 2012;3(1):68-90. PMID: 22500272

12. Sullivan SG, Feng S, Cowling BJ. Potential of the test-negative design for measuring influenza vaccine effectiveness: a systematic review. Expert Rev Vaccines. 2014;13(12):157191. https://doi.org/10.1586/14760584.2014.966695 PMID: 25348015

13. McLean HQ, Thompson MG, Sundaram ME, Kieke BA, Gaglani $M$, Murthy $\mathrm{K}$, et al. Influenza vaccine effectiveness in the United States during 2012-2013: variable protection by age and virus type. J Infect Dis. 2015;211(10):1529-40. https://doi. org/10.1093/infdis/jiu647 PMID: 25406334

14. Skowronski DM, Janjua NZ, De Serres G, Sabaiduc S, Eshaghi A, Dickinson JA, et al. Low 2012-13 influenza vaccine effectiveness associated with mutation in the egg-adapted $\mathrm{H}_{3} \mathrm{~N}_{2}$ vaccine strain not antigenic drift in circulating viruses. PLoS One. 2014;9(3):e92153. https://doi.org/10.1371/journal. pone.0092153 PMID: 24667168

15. Simpson CR, Lone NI, Kavanagh K, Ritchie LD, Robertson $C$, Sheikh A, et al. Trivalent inactivated seasonal influenza vaccine effectiveness for the prevention of laboratoryconfirmed influenza in a Scottish population 2000 to 2009. Euro Surveill. 2015;20(8):21043. https://doi.org/10.2807/15607917.ES2015.20.8.21043 PMID: 25742433

16. Pebody R, Warburton F, Andrews N, Ellis J, von Wissmann B, Robertson $C$, et al. Effectiveness of seasonal influenza vaccine in preventing laboratory-confirmed influenza in primary care in the United Kingdom: 2014/15 end of season results. Euro Surveill. 2015;20(36):30013. https://doi.org/10.2807/15607917.ES.2015.20.36.30013 PMID: 26535911

17. Rondy M, Launay O, Puig-Barberà J, Gefenaite G, Castilla J, de Gaetano Donati K, et al. European hospital IVE network. 2012/13 influenza vaccine effectiveness against hospitalised influenza $A\left(\mathrm{H}_{1} \mathrm{~N}_{1}\right)$ pdmo9, $A\left(\mathrm{H}_{3} \mathrm{~N}_{2}\right)$ and $\mathrm{B}$ : estimates from a European network of hospitals. Euro Surveill. 2015;20(2):21011. https://doi.org/10.2807/1560-7917.ES2015.20.2.21011 PMID: 25613779

18. Cheng AC, Kotsimbos T, Kelly PMFluCAN Investigators. Influenza vaccine effectiveness against hospitalisation with influenza in adults in Australia in 2014. Vaccine. 2015;33(51):7352-6. https://doi.org/10.1016/j. vaccine.2015.10.016 PMID: 26529066

19. Turner N, Pierse N, Bissielo A, Huang Q, Radke S, Baker M, et al. SHIVERS investigation team. Effectiveness of seasonal trivalent inactivated influenza vaccine in preventing influenza hospitalisations and primary care visits in Auckland, New Zealand, in 2013. Euro Surveill. 2014;19(34):20884. https:// doi.org/10.2807/1560-7917.ES2014.19.34.20884 PMID: 25188614

20. Kelly HA, Lane C, Cheng AC. Influenza vaccine effectiveness in general practice and in hospital patients in Victoria, 2011-2013. Med J Aust. 2016;204(2):76.e1-4. https://doi.org/10.5694/ mja15.01017 PMID: 26821109

21. Martínez-Baz I, Navascués A, Pozo F, Chamorro J, Albeniz E, Casado I, et al. Influenza vaccine effectiveness in preventing inpatient and outpatient cases in a season dominated by vaccine-matched influenza B virus. Hum Vaccin Immunother. 2015;11(7):1626-33. https://doi.org/10.1080/21645515.2015.10 38002 PMID: 25996366

22. McLean HQ, Thompson MG, Sundaram ME, Meece JK, McClure DL, Friedrich TC, et al. Impact of repeated vaccination on vaccine effectiveness against influenza $A\left(\mathrm{H}_{3} \mathrm{~N}_{2}\right)$ and $B$ during 8 seasons. Clin Infect Dis. 2014;59(10):1375-85. https://doi. org/10.1093/cid/ciu680 PMID: 25270645

23. Martínez-Baz I, Martínez-Artola V, Reina G, Guevara M, Cenoz MG, Morán J, et al. Effectiveness of the trivalent influenza vaccine in Navarre, Spain, 2010-2011: a population-based testnegative case-control study. BMC Public Health. 2013;13(1):191. https://doi.org/10.1186/1471-2458-13-191 PMID: 23496887

24. Castilla J, Martínez-Baz I, Martínez-Artola V, Reina G, Pozo F, García Cenoz M, et al. Decline in influenza vaccine effectiveness with time after vaccination, Navarre, Spain, season 2011/12. Euro Surveill. 2013;18(5):20388. https://doi. org/10.2807/ese.18.05.20388-en PMID: 23399423

25. Castilla J, Navascués A, Fernández-Alonso M, Reina G, Albéniz E, Pozo F, et al. Effects of previous episodes of influenza and vaccination in preventing laboratory-confirmed influenza in Navarre, Spain, 2013/14 season. Euro Surveill.
2016;20(22):30243. https://doi.org/10.2807/1560-7917. ES.2016.21.22.30243 PMID: 27277013

26. Instituto de Salud Pública y Laboral de Navarra. Protocolo de vacunación antigripal 2015-2016. [Influenza vaccination protocol 2015-2016]. Boletín Informativo. 2015;85:1-4. Spanish. Available from: https://www.navarra.es/NR/rdonlyres/ AECCD760-AB2A-4841-818A-FA53478FD6DC/326813/BOL8515 pdf

27. European Commission. Commission Decision of 28 April 2008 amending Decision 2002/253/EC laying down case definitions for reporting communicable diseases to the Community network under Decision No 2119/98/EC of the European Parliament and of the Council. Luxembourg: Official Journal of the European Union. 18.6.2008:L 159/46. Available from: http://eur-lex.europa.eu/LexUriServ/LexUriServ.do?uri=0):L:2 008:159:0046:0090:EN:PDF

28. Belongia EA, Simpson MD, King JP, Sundaram ME, Kelley NS, Osterholm MT, et al. Variable influenza vaccine effectiveness by subtype: a systematic review and meta-analysis of testnegative design studies. Lancet Infect Dis. 2016;16(8):94251. https://doi.org/10.1016/S1473-3099(16)00129-8 PMID: 27061888

29. McLean HQ, Meece JK, Belongia EA. Influenza vaccination and risk of hospitalization among adults with laboratory confirmed influenza illness. Vaccine. 2014;32(4):453-7. https://doi. org/10.1016/j.vaccine.2013.11.060 PMID: 24291201

30. Petrie JG, Ohmit SE, Cheng CK, Martin ET, Malosh RE, Lauring AS, et al. Influenza vaccine effectiveness against antigenically drifted influenza higher than expected in hospitalized adults: 2014-2015. Clin Infect Dis. 2016;63(8):1017-25. https://doi. org/10.1093/cid/ciw432 PMID: 27369320

31. Jackson LA, Jackson ML, Nelson JC, Neuzil KM, Weiss NS. Evidence of bias in estimates of influenza vaccine effectiveness in seniors. Int J Epidemiol. 2006;35(2):337-44. https://doi.org/10.1093/ije/dyi274 PMID: 16368725

32. Carrat F, Vergu E, Ferguson NM, Lemaitre M, Cauchemez S, Leach S, et al. Time lines of infection and disease in human influenza: a review of volunteer challenge studies. Am J Epidemiol. 2008;167(7):775-85. https://doi.org/10.1093/aje/ kwm375 PMID: 18230677

33. Martínez-Baz I, Casado I, Navascués A, Díaz-González I, Aguinaga A, Barrado L, et al. Effect of repeated vaccination with the same vaccine component against 2009 pandemic influenza $A\left(\mathrm{H}_{1} \mathrm{~N}_{1}\right)$ virus. J Infect Dis. 2017;215(6):847-55. https://doi.org/10.1093/infdis/jix055 PMID: 28453845

\section{License and copyright}

This is an open-access article distributed under the terms of the Creative Commons Attribution (CC BY 4.0) Licence. You may share and adapt the material, but must give appropriate credit to the source, provide a link to the licence, and indicate if changes were made.

This article is copyright of the authors, 2018. 